\title{
High Waste Rock Dumps — Challenges and Developments
}

\author{
L. Valenzuela Arcadis Geotecnica, Chile \\ E. Bard Arcadis Geotecnica, Chile
}

J. Campaña Arcadis Geotecnica, Chile

M.E. Anabalón Arcadis Geotecnica, Chile

\begin{abstract}
The recent experience with the design and operation of very high waste rock dumps (WRD) is discussed with special emphasis on the determination of the geotechnical characteristics of waste rock subject to high confining pressures and eventually also subject to in situ leaching. The results of drained and undrained triaxial tests on samples of waste rock, carried out on a recently built apparatus capable of accepting samples of $1 \mathrm{~m}$ in diameter and up to $203.2 \mathrm{~mm}$ size and confining pressures up to 3 MPa are commented on. The use of these results in the analysis of possible static liquefaction is also discussed as well as the design approach to consider earthquake effect and final closure of the facilities.
\end{abstract}

\section{Introduction}

The production of many of the world's greater open pit metallic mines has increased dramatically with an immediate impact over the demand for bigger and usually higher WRD. Today, production levels of over 150,000 tons of treated mineral per day or even over 200,000 tons per day are not uncommon and consequently the requirement for the daily disposal of 300,000 to more than 400,000 tons of waste rock. If these high production levels are combined with mine locations in mountainous environments where the only available space for WRD are relatively narrow and sometimes also steep valleys, fairly high WRD could be required. Actually, in the last two decades, some dumps with heights of the order of 400 to $500 \mathrm{~m}$ have been reported in Canada, Chile and other mining countries.

In the case of Chile for instance there are already dumps under operation that will reach final heights of more than $500 \mathrm{~m}$. But some of these mines are presently considering expansions of their production that would require in the near future $700 \mathrm{~m}$ high WRD or even higher. This type of structure will be the highest ever built by man, requiring a careful consideration of all the factors involved in their present and long-term behaviour. With these structures the industry, geotechnical practitioners and researchers are facing a major challenge that will require a significant joint effort to find adequate solutions to the many problems involved.

\section{Main challenges presented by high WRD}

Many are the challenges presented by WRD and especially by high WRD. Among the most significant ones are the following.

\subsection{Geotechnical behaviour of waste rock material under high confining pressures}

For very high WRD one could expect that the high confining stresses could influence in some way the main geotechnical characteristic of typical waste rock material such as: shear strength, deformability and permeability. The probable crushing of rock particles producing finer material could also play a major role in the final behaviour of the waste rock mass.

\subsection{Geotechnical behaviour of waste rock under in situ leaching}

In situ leaching of the deposited waste rock could be produced naturally by acid generation or in a forced way, irrigating the WRD with water and sulphuric acid to recover metals. In both cases there are complex phenomena that could produce the degradation of the rock particles producing finer material, thus affecting 
the strength, deformability and permeability of the waste rock mass. In this case the behaviour in the medium and long-term could be quite relevant.

In the specific case of natural acid generation the question of how to control this acid generation could be also a major issue due to the impact on environmental conditions.

\subsection{Engineering and operation of high WRD}

The need of engineering the WRD and specifically high WRD is not always on the mind of mining operators. The idea of a waste that is dumped in the cheapest possible way with eventual failures generally not representing major consequences is still the most common idea of what should be the approach to WRD. An increasing number of mining companies are finding that the sustainable solution for the disposal of both waste rock and tailings could constitute determining factors in the feasibility of some projects. Not only the proper engineering design of WRD is necessary to be implemented in the mining practice, but also a significant research effort is needed to support such designs.

It is quite pertinent to quote here what professor Norbert Morgenstern (1996) stated in his keynote lecture in the ICOLD meeting that was held in Santiago-Chile: "This keynote address is driven by urgency, ..........it has become apparent that the technical and managerial challenge of responsible mine waste management is under-recognised and that the contributions that geotechnical engineers can make to meet this challenge is under-appreciated."

\subsection{Possible modes of failure of high WRD}

There is relatively scarce well documented information about the failure of WRD, although almost every big mine has had an episode that generally has been treated as an operational accident, without registering the geotechnical and engineering characteristics of each event, probably because in those cases there was not a big impact on human lives and on the environment. In this way several opportunities to learn more about the possible failure mechanisms and the role played by different aspects such as foundation conditions, operational practices, grain size characteristics and water content of waste rock, rain and snow conditions, drainage conditions and possible pore water pressure build up, and other important aspects have been lost.

The well known case of the Aberfan disaster produced by the failure of a colliery waste dump in 1966 (Bishop, 1973) raised the possibility that flow slides could occur in coarse material deposited initially in dry conditions. The same type of phenomena has been associated with the failure of some WRD in Canada (Dawson et al., 1998: Hungr et al., 2002), in research dedicated to the study of the more than 50 failures of WRD in the coal mining industry, many of them involving flow slides with considerable run out distances, associated with the static collapse of saturated or nearly saturated sandy gravel layers within the dumps (see Figure 1).

Campbell (1986) suggested, based on his observations in the coal industry in Canada, that the failure of some of these high WRD could be related to what he called the "double wedge system" in which the lower wedge comprising the toe region of the WRD is supporting the upper wedge, which is in an active Rankine state. Although this model has also been mentioned in other works describing operation and monitoring considerations in WRD design and operation in British Columbia, Canada, there is not enough information that supports this assumption.

In the 2004 International Conference on Landslides in Río de Janeiro, an example of a failure of a $515 \mathrm{~m}$ high WRD in a copper mine in Chile was discussed (Valenzuela, 2004), in which the failed mass reached an abandoned open pit and then climbed the opposite wall of the pit up to a height of $75 \mathrm{~m}$ over the pit bottom (Figure 2). This is one of the few cases of a big failure of WRD not belonging to the coal industry, but no detailed investigation was carried out after failure. 


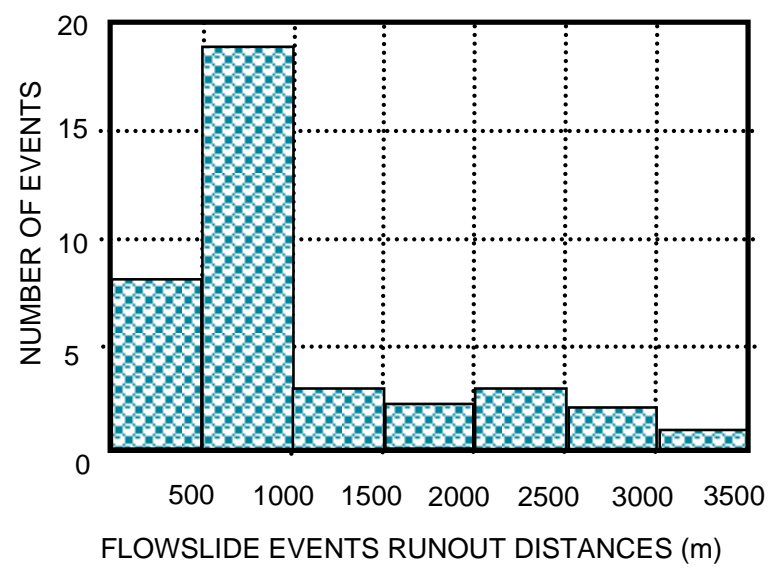

Figure 1 British Columbia coal mine waste dump runout statistics (Dawson et al., 1998)

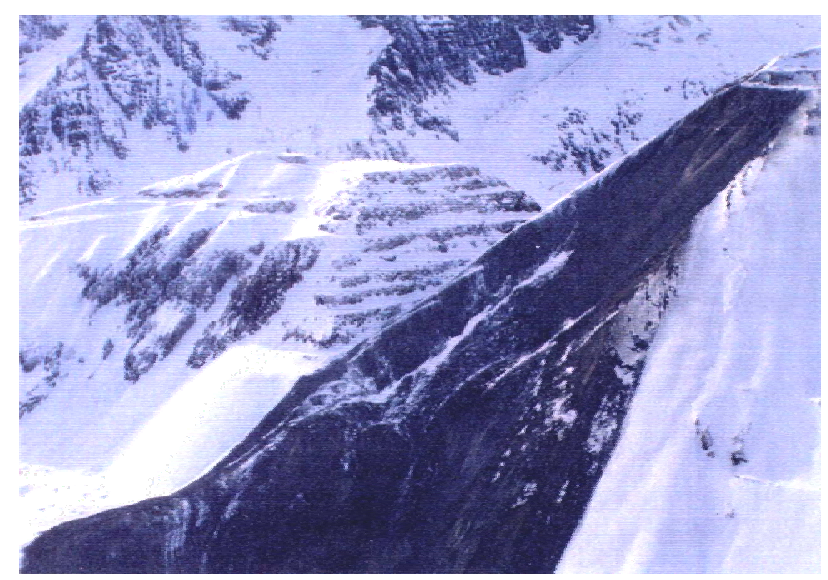

Figure 2 Failure of a $515 \mathrm{~m}$ high WRD in a copper mine in Chile (Valenzuela, 2004)

Waste rock flow slides could be triggered by static liquefaction. Liquefaction can be initiated either by static or dynamic loads. In the case of static liquefaction, a loose contractant saturated or almost saturated cohesionless mass must be brought to the onset of yield, which is close to undrained failure. This may be induced by undrained stress paths such as rapidly applied external loads or strains as well as drained stress paths such as an increase in water pressure. In either case, at yield, the loose contractant system attempts to decrease in volume. This is restricted by the incompressible water, resulting in a transfer of load to the water phase and an increase in pore pressure. The effective stress is suddenly reduced, inducing a loss in shear strength, often to the degree that this granular system can flow. If the waste rock mass is inadequately confined, a liquefaction flowslide results.

In order for static liquefaction to occur, a number of conditions must be satisfied. The material must have high enough sand and fines content to sustain pore pressures. The structure must be loose enough to contract during applied shear stresses. The void space must be saturated or nearly so. In addition there must be a triggering mechanism.

Waste dumps constructed under seemingly dry conditions over strong, free-draining foundations would not appear to be exposed to liquefaction flowsliding. However, over the past thirty years or so a substantial number of long runout waste dump flowslides have been reported in coal mines of British Columbia as already mentioned. Failures, including fatalities, have occurred also at abandoned dumps indicating that the triggering mechanism is not uniquely tied to active dumping (Morgenstern, 2001). 
Figure 3 shows the stress paths derived from large triaxial test, on the fine matrix of leached copper waste dump materials (Valenzuela, 2004). Observe the decrease in undrained shear stress with the increase of confining pressure and compare with similar behaviour shown in Figure 6, obtained for waste rock material.

\subsection{The three dimensional aspect of WRD stability analysis}

In very narrow valleys the behaviour of high WRD could be influenced by three dimensional effects at least in the way a design earthquake is considered in a dynamic analysis. This is an aspect that has been discussed mainly at a theoretical level but some more research, instrumental data and actual performance records are needed in order to establish more accurate seismic design guidelines.

An approach to the solution of this aspect is modelling the narrow valley without the WRD and then to obtain the seismic site effect: in term of amplification of the acceleration and then to impose this boundary condition in the dynamic analysis of the WRD. Figure 4 shows the results of modelling these effects using FLAC 3D.

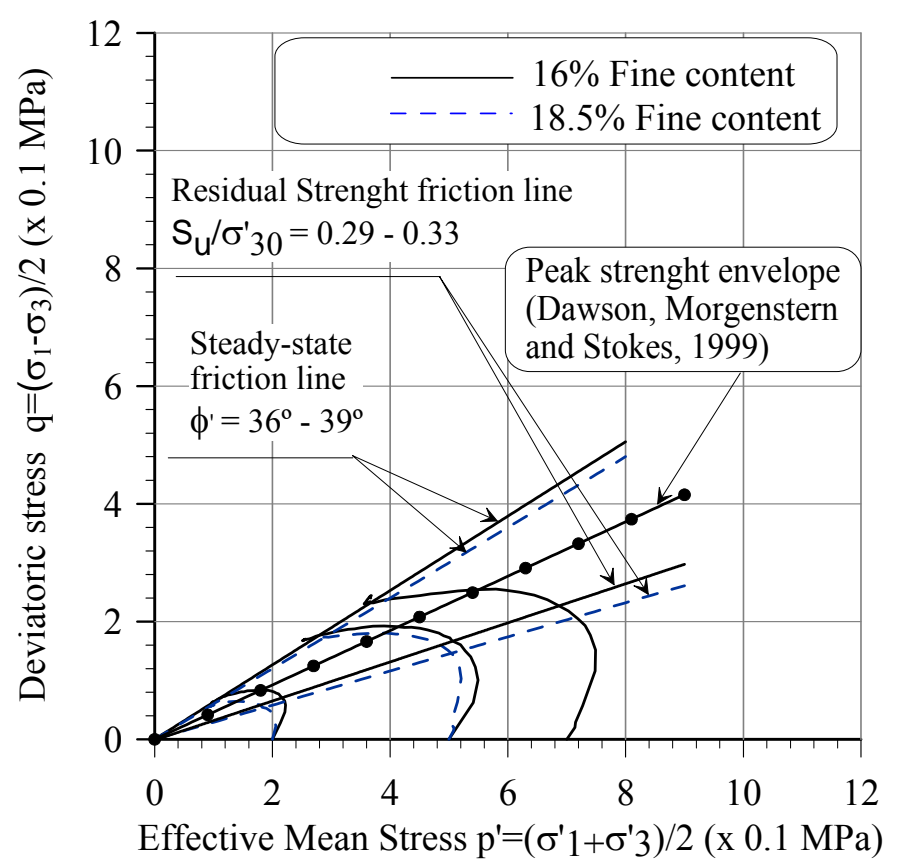

Figure 3 Stress paths derived from CIU triaxial test on the fine matrix leached copper waste dump material (Valenzuela, 2004) 


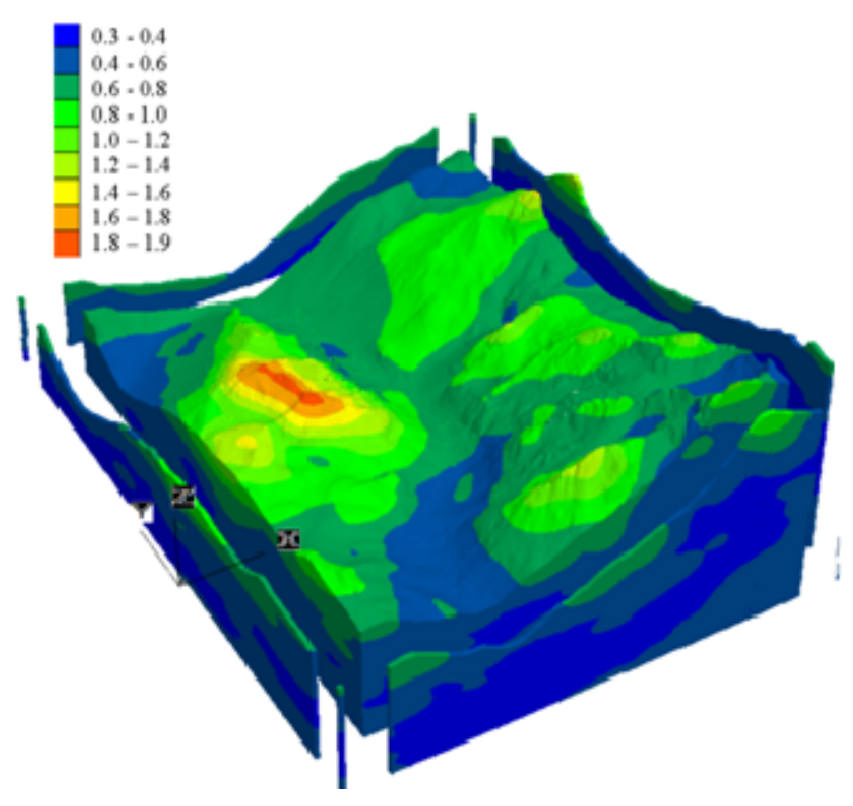

Figure 4 Modelling of seismic site effect in a narrow valley. Contour of different ground velocities in $\mathrm{m} / \mathrm{s}$ (Arcadis, 2006)

\subsection{Reliable and robust geotechnical instrumentation}

One of the problems faced when studying the behaviour and performance of WRD is the lack of instrumented records of deformations, pore water pressure, pressure distribution, seismic response of the waste rock mass and even of reliable simple measurements such as superficial displacements. There is the need for designing and manufacturing new and robust instrumentation systems that could survive in a very tough environment with large deformations, heavy rock transport equipment and eventually aggressive chemical environment, allowing remote readings and registration.

\subsection{Characterisation and modelling of heterogeneous material}

Waste rock can be an extremely heterogeneous material with grain size particles ranging from fine soil to large boulders of few metres. Also there is the presence of different lithologies and also different mechanical rock qualities. The dumping process used to form the WRD produces the segregation of the material mainly according to the particle size. In complicated cases when there are serious stability and environmental issues, the adequate solution many times requires to have a well controlled construction procedure, defining a dump in layers with pre-defined thickness and eventually with selection of the type of waste for different sectors of the deposit. To model the deposit of such heterogeneity for analysis is generally a very rough approximation.

\section{New developments in laboratory testing of coarse material}

Laboratory equipment and procedures have been limited by sample size and level of confining stresses; consequently the data available mainly correspond to the relatively fine part of actual rock fills and for confining pressures in general less than $1 \mathrm{MPa}$. There is an evident need for larger laboratory tests and for representative in situ tests.

\subsection{In situ grain size distribution}

The in situ particle size distribution resulting in a WRD is difficult to determine for many reasons such as the heterogeneity of the material deposited, the segregation occurred during the dumping process and the possible degradation or increase of fines due to high stresses and/or to natural or forced leaching.

To characterise the waste rock, it is recommended to perform in situ grain size distribution tests at large scale, and at different depth levels of the WRD. A complementary approach is to estimate the grain size distribution from processed digital images obtained from exposed slopes. 


\subsection{Shear strength}

There are reasonable doubts about the actual representativeness of existing constitutive laws and failure criteria for very coarse materials, deposited in a loose state and subject to high confining stresses. There is not enough experimental data as well as properly monitored actual behaviour of high WRD that could give reasonable comfort with these special conditions (Valenzuela et al., 2007).

Recently, the Instituto de Investigación y Ensayos de Materiales (IDIEM) based at Universidad de Chile has implemented a triaxial equipment of controlled loads, capable of reaching confining pressures of $2.5 \mathrm{MPa}$, with large size samples, of up to $1.0 \mathrm{~m}$ in diameter and $1.8 \mathrm{~m}$ in height. According to these dimensions, the materials tested could present a maximum size up to $203 \mathrm{~mm}$. The equipment (see Figure 5) has a reaction frame designed for a maximum working load of $20 \mathrm{MN}$ and a testing chamber shaped like a bottle with an interior diameter of $1.74 \mathrm{~m}$ and $2.66 \mathrm{~m}$ in height. It has six lower entrances for high pressure hoses and eight connectors for sensors. The volumetric control is accomplished with the use of a high pressure tank, located on a support frame with a loading cell that records, by weight, the volumetric change of the sample. The air and water pressures are regulated through a master panel while the control is performed with a double system of precision manometers and pressure sensors. The load on the sample is applied with four hydraulic jacks with the control performed through a loading cell of $5 \mathrm{MN}$ of capacity. The deformation control is done through three displacement sensors, attached to the loading piston and located equidistant from each other. In addition, three pressure sensors are used, one for the control of the pressure chamber and the remaining two for the control of the pressures inside the sample (counter pressure and pore pressure). Finally, data acquisition during the test is carried out with an analogue-digital system.

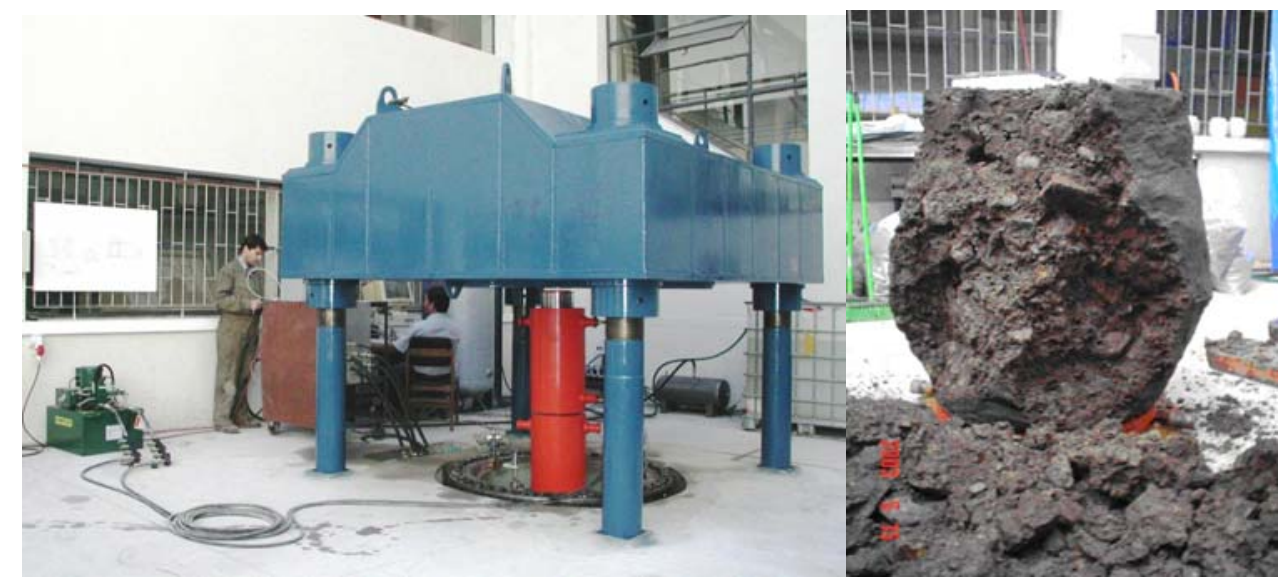

Figure 5 Loading frame (left) and sample after testing, $D=0.6 \mathrm{~m}$ and $\mathrm{H}=1.0 \mathrm{~m}$ (right). Large scale triaxial equipment (Bard et al., 2007a)

For the different types of waste rock recently tested (Bard et al., 2007a), samples obtained from run of mine (ROM) material and leached material of a copper mine in Chile, the results of triaxial test (CID and CIU) show that the shear strength is reduced progressively as the level of applied pressures is increased (see Figure 6). This is mainly because of the increase in compressibility of the granular matrix due to the increase in the level of pressures that is accompanied by an evolution of the initial grain size to a finer grain size distribution. It is also observed that for lower pressures the tendency towards volumetric dilation disappears, for confining pressures above $0.2 \mathrm{MPa}$. 

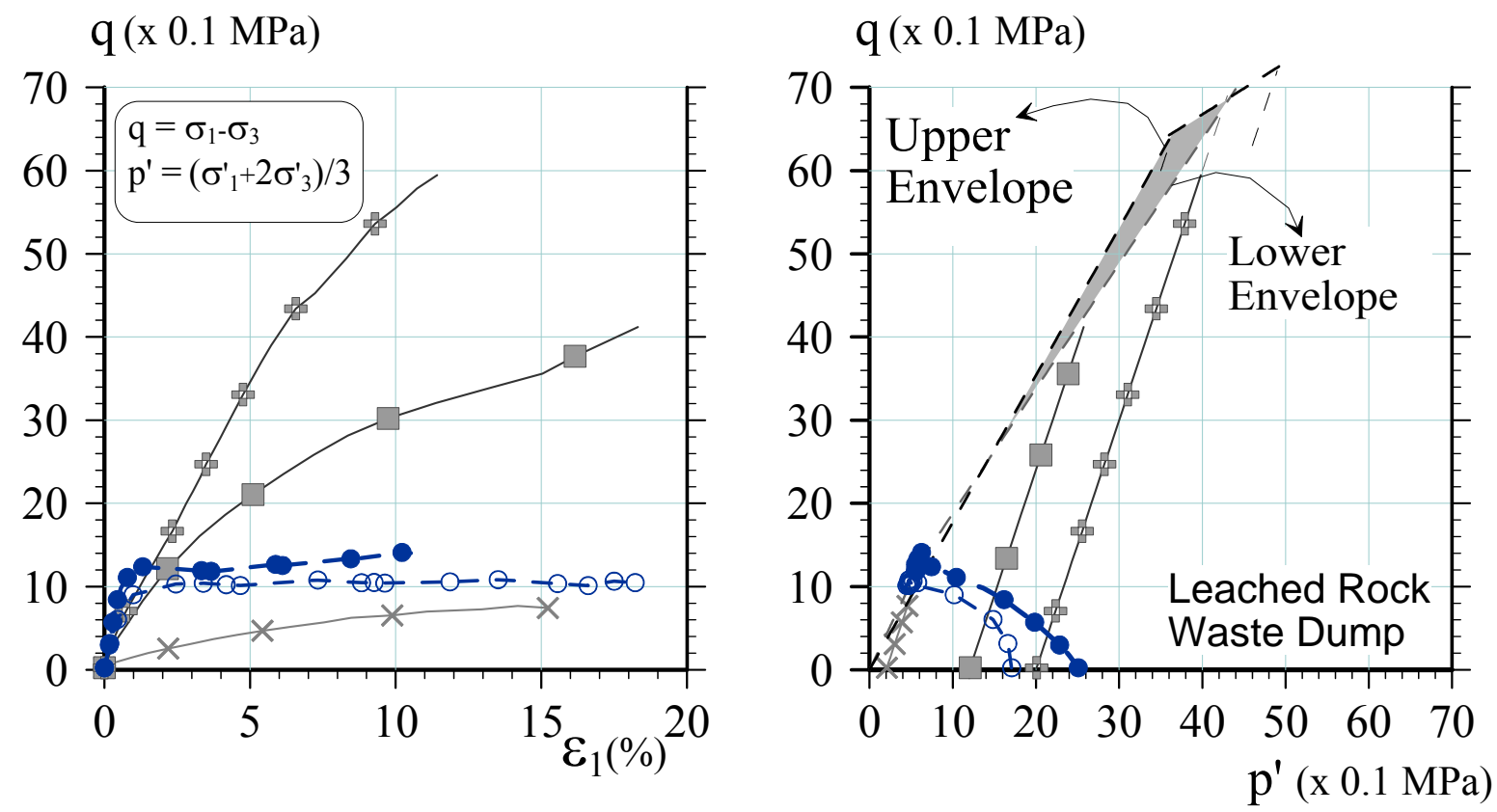

Figure 6 Results of triaxial tests. Sample of leached waste rock (Bard et al., 2007)

The strength envelope shown in Figure 6 is characterised at low pressures by a high internal friction angle and null cohesion. At higher stress levels, a progressive reduction in the slope of this envelope is observed, which gives origin to its curvature, as a result of the greater compressibility of the granular matrix associated with the phenomenon of particle crushing, implying a decreasing of the internal friction angle. Given the relatively loose initial state of the waste rock, these materials present contractive behaviour for confining pressures above $0.2 \mathrm{MPa}$ (tendency for volume decrease), which is accentuated for higher pressures. In effect, the e- p' plot (Figure 7) shows that the compressibility of the material increases significantly for confining pressures over $1 \mathrm{MPa}$ (ROM and leached material). The undrained strength $\left(\mathrm{Su} / \sigma^{\prime}{ }_{30}=0.28-0.29\right)$ is similar to results obtained on the fine matrix of leached copper waste dump material (Valenzuela, 2004) shown in Figure 3.

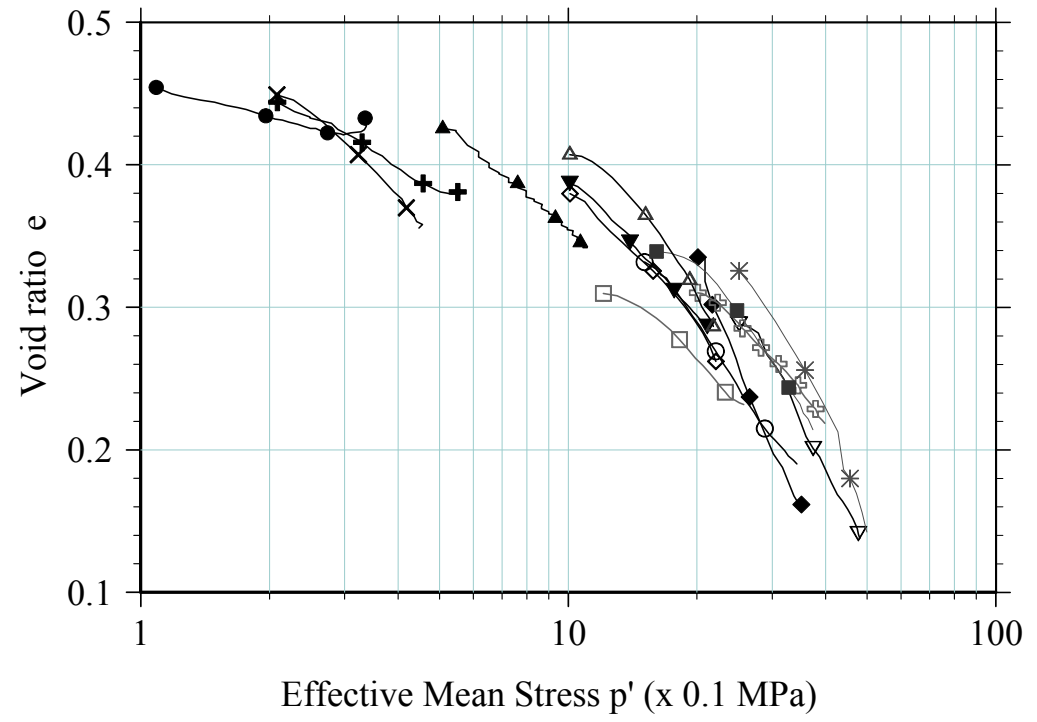

Figure 7 Typical results of compressibility obtained from triaxial tests on WRD material (e-p' plane). Copper mine sample (Bard et al., 2007a) 
Figure 8 shows the shear strength envelopes, deduced from the performed tests, plotted in the Mohr plane $\left(\tau, \sigma_{\mathrm{n}}^{\prime}\right)$, in addition to those reported in the technical literature for coarse granular materials coming from hard rocks (Marsal et al., 1975). As observed in this figure, the results obtained from the waste rock are well positioned within the proposed envelopes for shear strength for these materials, especially for the range of pressures below $\sigma_{\mathrm{n}}^{\prime}=2 \mathrm{MPa}$. For a higher level of stresses, the strength envelopes start to curve, due to the greater compressibility of the granular matrix associated with the crushing of particles (Biarez and Bard, 1992).

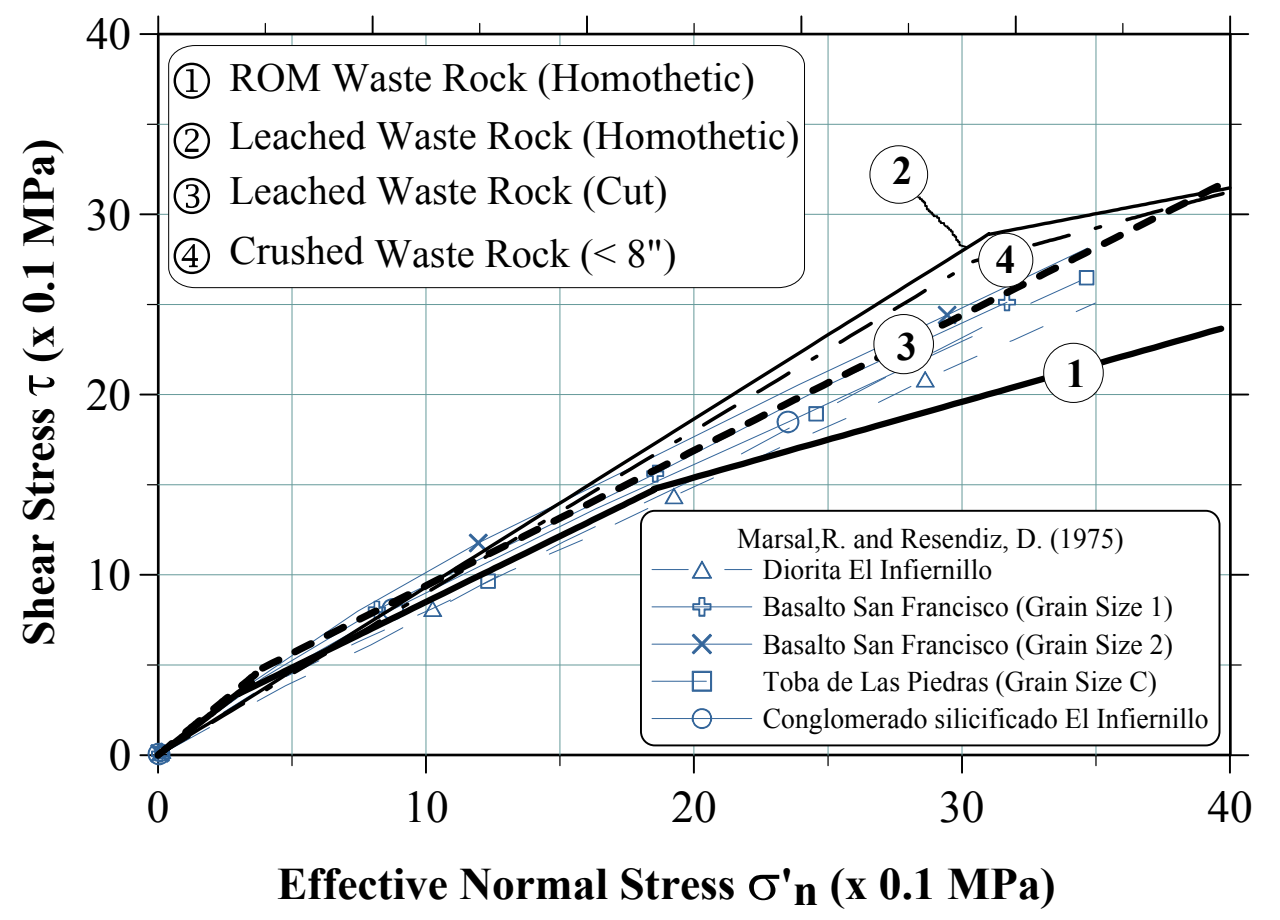

Figure 8 Envelopes of the waste rock in the Mohr plane. Copper mine sample (Bard et al., 2007a)

\subsection{Evolution of density}

The high pressures associated with the weight of the materials stockpiled in waste rock dumps with heights over $100 \mathrm{~m}$ induce significant particle crushing, modifying the initial grain size distribution of the material and leading to an increase in the amount of sands and fines in the granular matrix. This condition modifies the void ratio and consequently changes the permeability and density.

The evolution of density could be obtained from laboratory tests simulating the in situ conditions. The large scale oedometer test is an adequate test to obtain the evolution of void ratio according to the increase of vertical load. Figure 9 shows the result of a large oedometer test performed on waste rock material compared with results from large scale triaxial tests.

The oedometer test results are plotted in Figure 10, showing the evolution of the dry density with the effective mean stress p', deduced from the vertical stress $\sigma_{\mathrm{v}}^{\prime}$ applied, and associated with the equivalent overburden height of the dump.

The values plotted in Figure 10 correspond to the dry density obtained at the end of the test or load phase. This figure also includes the results of the triaxial test that reached maximum pressures up to $\mathrm{p}^{\prime}=5 \mathrm{MPa}$, equivalent to a vertical stress of approximately $\sigma_{\mathrm{v}}^{\prime}=8.5 \mathrm{MPa}$. It is important to mention that for the triaxial results, the height of the dump is correlated to the mean stress reached at the end of the test, assuming that the stress state in the interior of the deposit, far away from the area of influence of the slopes, is close to the geostatic state, this is, $\sigma_{H}^{\prime}=k_{o} \cdot \sigma_{v}^{\prime}$, where $k_{o}$ is the coefficient of lateral earth pressure at rest. 


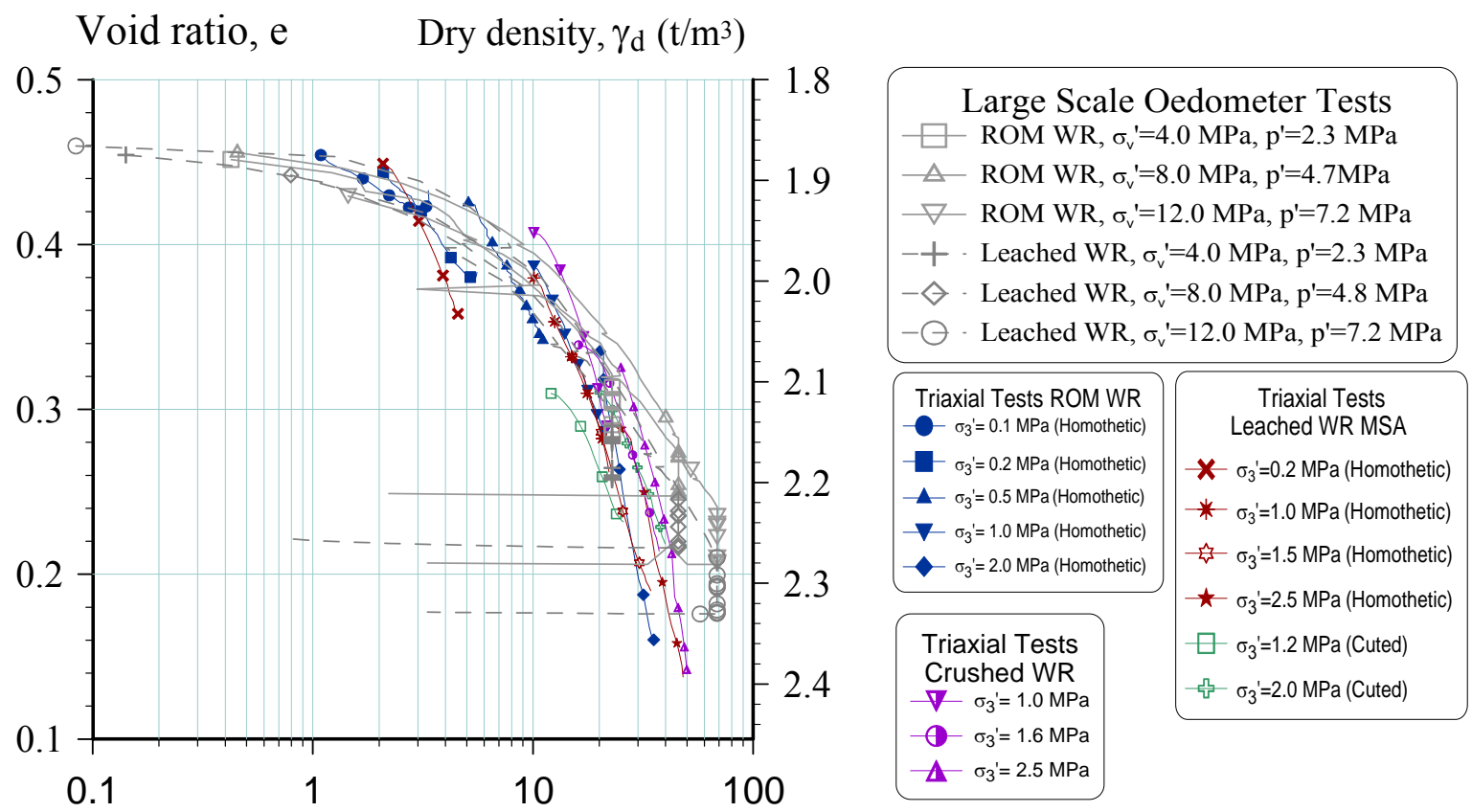

Effective Mean Stress p' (x 0.1 MPa)

Figure 9 Comparison of large triaxial and oedometer tests (Arcadis, 2006-2007)

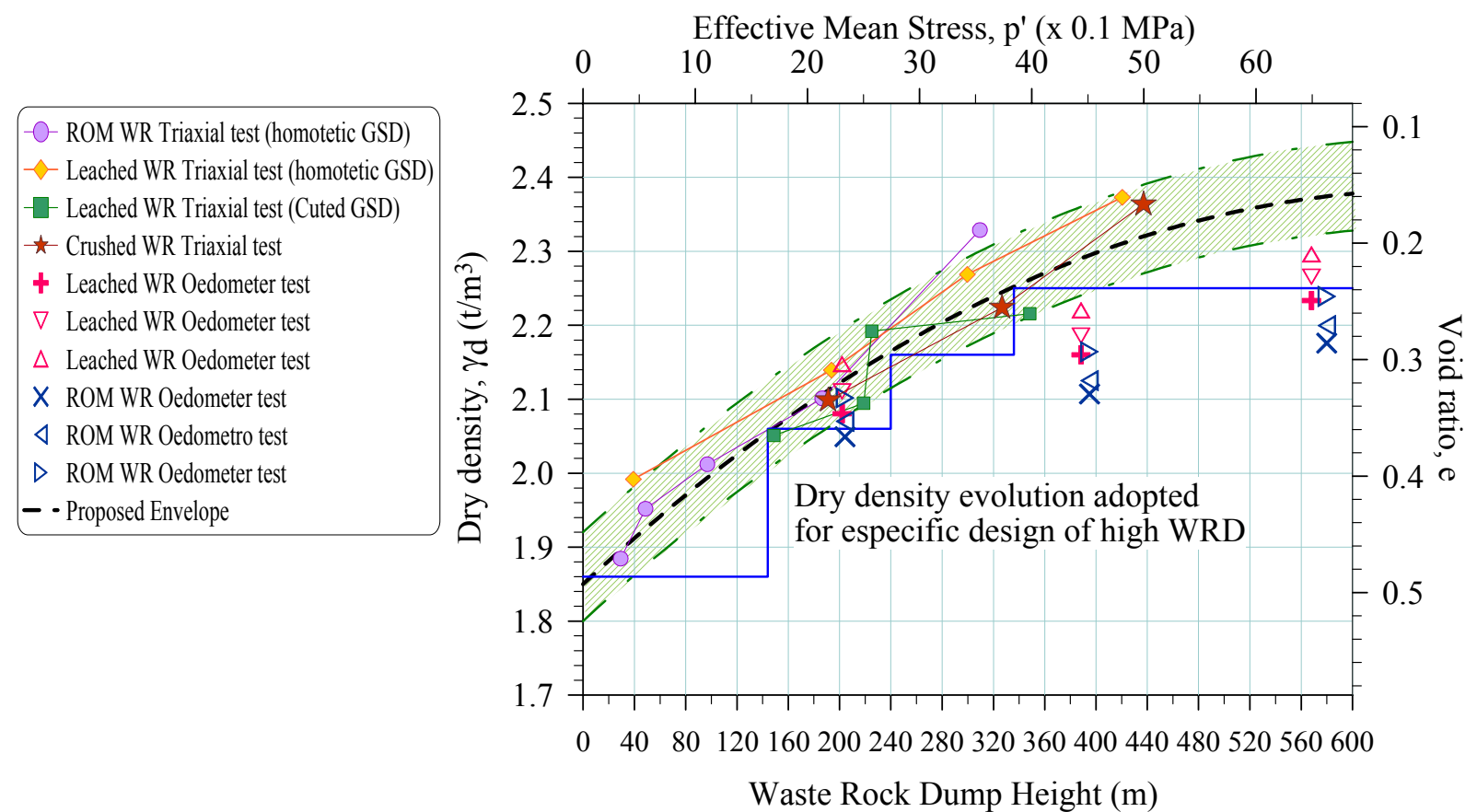

Figure 10 Evolution of dry density with waste rock dump height. Obtained from results of triaxial and oedometer test (Arcadis, 2006-2007) 


\section{Particle crushing due to high confining pressures}

As already mentioned, the high pressures associated with the weight of the materials stockpiled in waste rock dumps with heights over $100 \mathrm{~m}$ induce particle crushing, modifying the initial grain size distribution of the material and leading to an increase in the amount of sands and fines in the granular matrix. To evaluate this phenomenon, a systematic post-test grain size analysis in the waste rock has been performed in samples for a copper mine in Chile, obtaining the results presented in Figure 11.

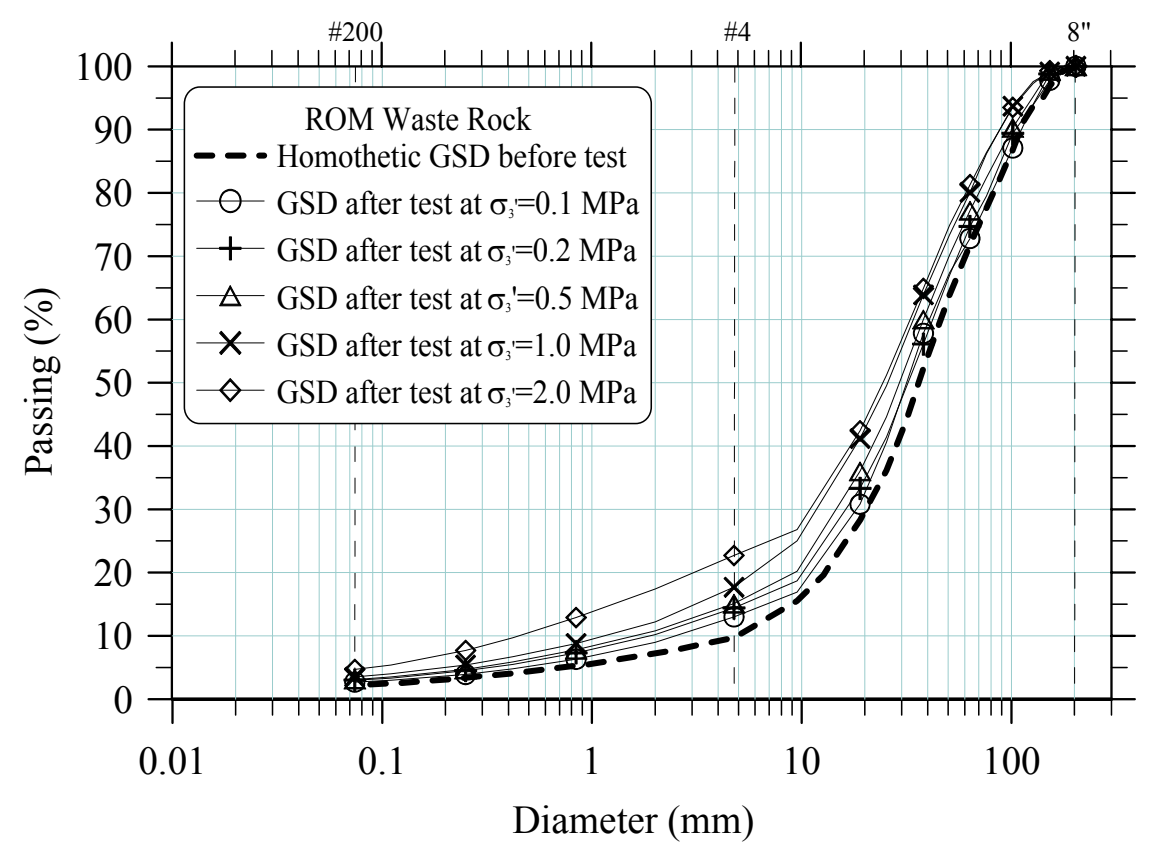

Figure 11 Grain size distribution (GSD), pre and post triaxial test - ROM (Bard et al., 2007b)

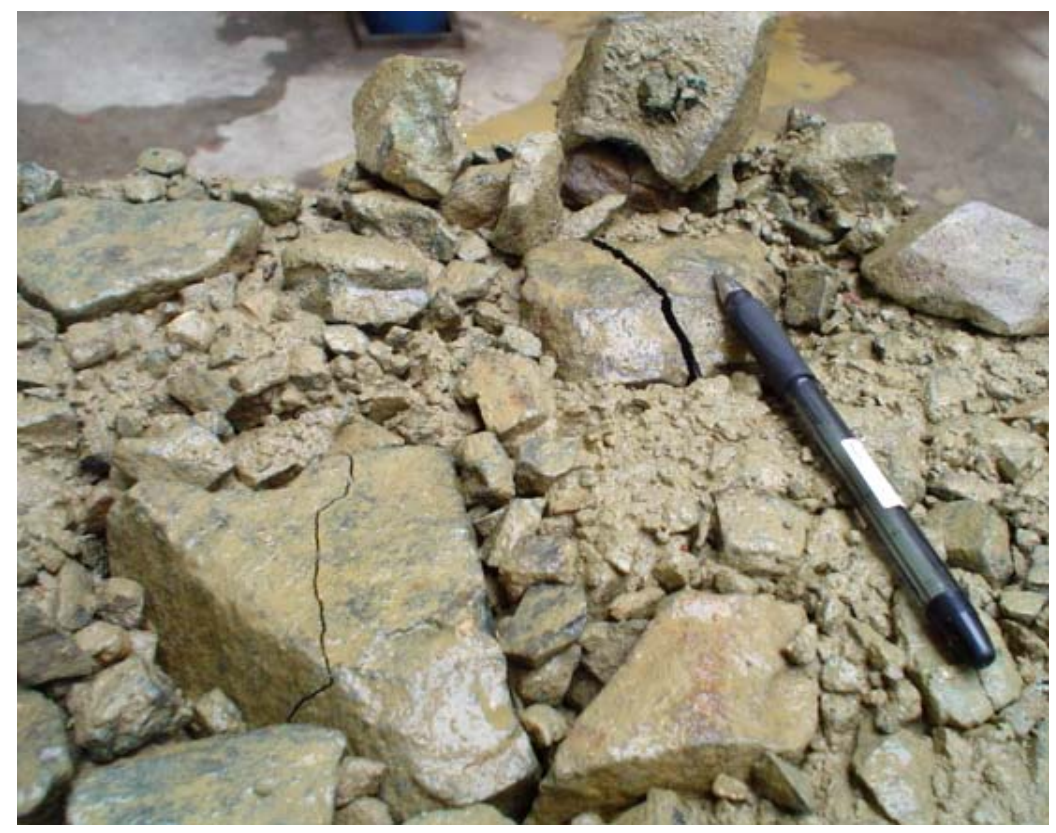

Figure 12 Detailed crushing of particles, after triaxial test (Bard et al., 2007a)

The analysis of these results allows for the following comments:

- As the final effective mean stress p' is increased, the particle crushing is manifested through the evolution of the initial grain size of the sample towards finer grain sizes, clearly increasing the sands content and, in lesser proportion, increasing fines. 
- For the different initial grain size distribution tested it was observed that the particle crushing was more significant in the coarser grain sizes, given that the grains present fewer points of contact with each other, which generate larger loads at these points. This effect is more progressive when dealing with angular to subangular particles.

- For larger confining pressures, the final grain size curves, originating both from cut grain size distribution as well homothetic grain size, evolve to a single grain size curve. This result is important, since it indicates that waste rock coming from rocks with similar mechanical characteristics but with different initial grain size, resulting from blasting, loading, segregation, and/or process conditions, will evolve to a similar grain size. This result has been observed before in materials with friable grains and sands (Bard, 1993).

\section{Effect of in situ leaching on waste rock}

Some high WRD have been irrigated with solution to produce an artificial leaching process and recover the remaining copper. Leaching increases the degree of saturation of the waste and weakens the fragments, creating and possibly concentrating fines. As a result, saturated conditions could build up in time and static liquefaction might be initiated in a leach cell resulting in a liquefaction flowslide.

More research is needed in order to fully understand the effects of the chemical degradation, and its effects on the mechanical behaviour of waste rock materials.

\section{Stability analysis and design considerations}

High WRD are challenging structures and construction practice should be improved, adopting a number of defensive measures to reduce potential instabilities.

Dump design must be consistent with the stability criteria adopted. In steep valleys, it is necessary to consider dump lifts of a certain height, compatible with the pit benching height and truck operations. This is in order to reduce the height of the advancing face and excessive segregation of the waste, both conditions conducive to potential instabilities. Also, the design criteria should be in accordance with the closure plan, to avoid a large and almost impracticable waste management at a later stage. In fact, the design criteria have to avoid designs resulting in unnecessarily restrictive requirements at the closure stage.

Considering the mechanical behaviour of the waste rock at high pressures, subjected to overburden stresses well beyond precedent, the front slope of a dump should be designed with a smooth global angle, much flatter than $37^{\circ}$, with the objective of generating a smaller loaded zone destined to constitute a high strength and high permeability buttress. The decrease of the stresses in the waste rock forming the buttress will contribute to reduce degradation effects on the materials due to both mechanical and leaching (natural or forced) actions.

Gentle slopes are obtained by building up the WRD in layers instead of dumping the waste rock at full height. The different lifts, with local slopes of around $37^{\circ}$ each, should include intermediate berms to control eventual local instabilities (one lift). To control potential instabilities affecting more than one lift, it is recommended to include a large berm every certain number of lifts, according to the global stability. An example of the application of this recommendation is presented in Figure 13, showing the final geometry of a high WRD, placed in a narrow mountainous valley in a highly seismic area. Figure 14 shows an example of stability analysis using limit equilibrium method (LEM). This analysis was complemented with dynamic analysis and $3 \mathrm{D}$ stability analysis using LEM.

Advancing faces of each lift should attempt to develop convex patterns where practical to encourage threedimensional restraints. Also, advancing faces should constitute a buttress to provide adequate containment and stability to waste rock, and must be constructed of good quality, low fines waste. Wet fine wastes or low resistance materials should be encapsulated in cells, placed behind the buttress. To fulfill this management of waste materials, sand and fines content of the waste should be checked on a periodic basis (Morgenstern, 2006). 


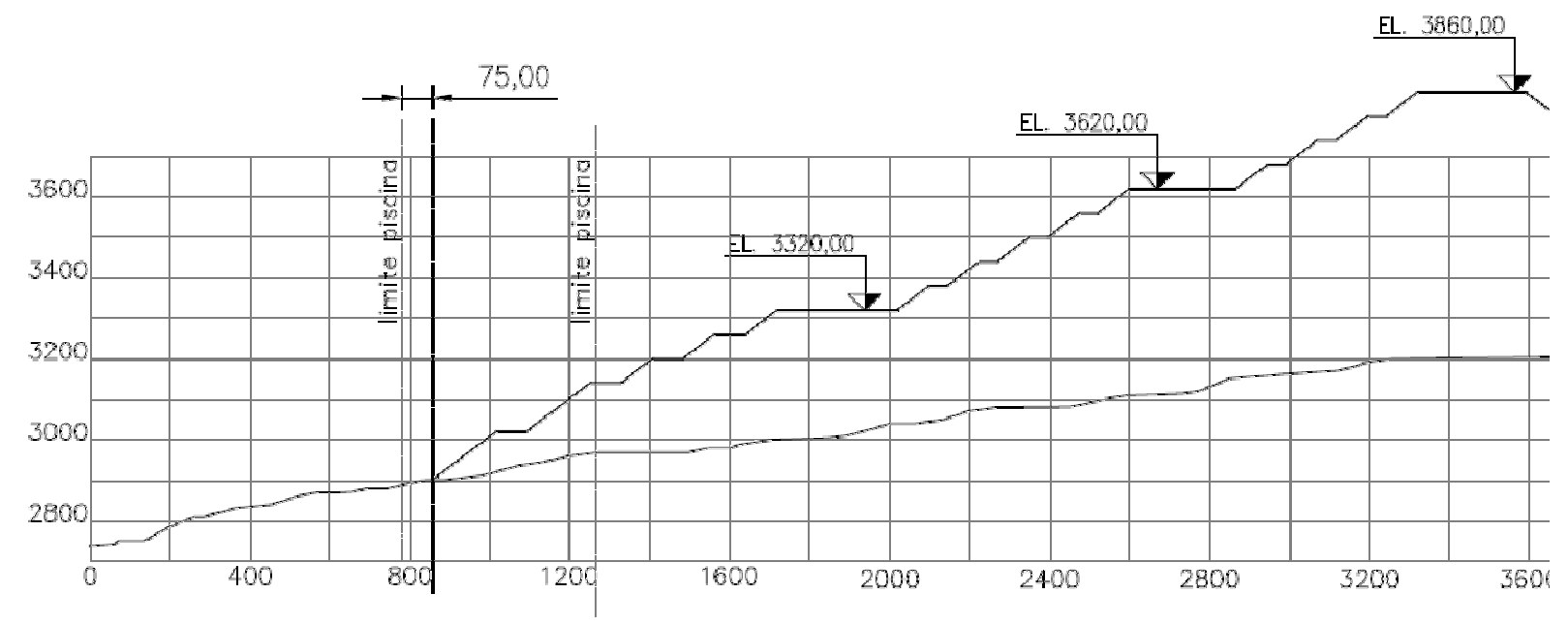

Figure 13 Final geometry of high WRD built in mountainous and high seismic area (Arcadis, 20062007)

$\mathrm{S} 1: \mathrm{WR}, 0$ to $200 \mathrm{~m}$.

S2: WR, 200 to $400 \mathrm{~m}$.

S3: WR similar S1 under leach process.
S4: WR similar S2 under leach process.

S5: WR, 400 to $600 \mathrm{~m}$, undrained.

S6: Foundation soils.

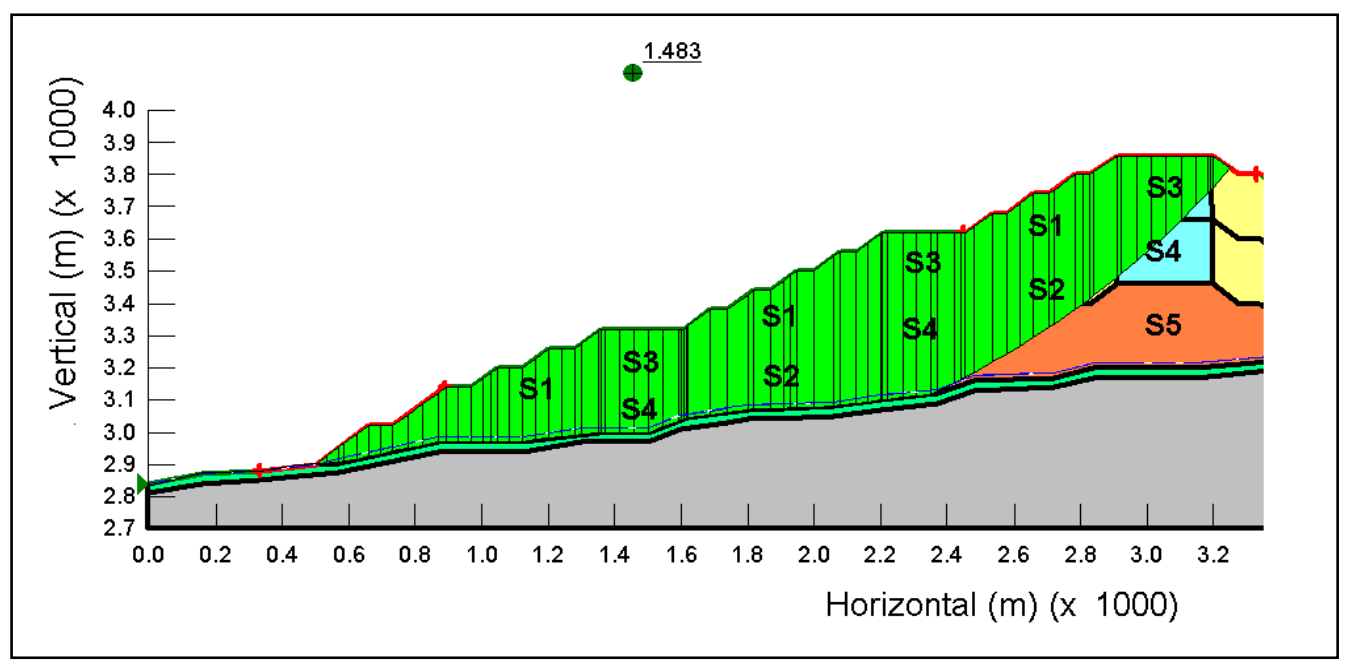

Figure 14 Example of stability analysis using ELM. Static case (Arcadis, 2006-2007)

\section{Other design and operational considerations}

There are many design and operational aspects to be considered when planning and designing a WRD and especially a high WRD.

\subsection{Basal drainage system}

Drainage system in a WRD is a critical aspect. The general practice used in most of the mines is to take advantage of the segregation in grain size produced during the dumping process and to rely on the permeability of the layers formed by the coarser rock blocks deposited at the bottom of the WRD layer. This practice has shown to be valid for many cases where "normal" conditions prevail, but there are also several conditions where a drainage system of this type could fail in the sense that it will not able to freely drainage the WRD, thus eventually producing an increase in the pore water pressure at foundation level or in the zone above the contact between two layers. Such "abnormal" conditions could be produced in areas with 
extremely high water precipitation, deterioration of the drainage rocks because natural or forced weathering and or increase of the content of fine particles due to high confining stresses. The solution for these cases is not easy but generally consists in selecting sound and ideally inert rocks to form the drainage system, to build a separate drainage system before the formation of the WRD and even to build such "artificial" drains within a trench in order to avoid the effect of high stresses.

\subsection{Water management}

A water plan for the dump has to be developed, in order to divert surface runoff away from the dump, both for stability and environmental considerations. This plan has to include solutions to avoid excessive watering of the dump. For instance, to provide adequate drainage of the dump platform, cracks should be sealed by scarification and compaction in periods of potential infiltration, among others (Morgenstern, 2006).

Due to either traffic on the dump platforms and/or to the deposition of fine waste, the surface could become highly compacted and relatively impervious and perched water tables could develop, creating conditions for static liquefaction. Zonation of the materials in the WRD could be considered in some cases in order to avoid these types of problems.

\subsection{Foundation conditions}

Local deformations produced by weak foundations could become the triggering mechanism for a major failure. In these cases the weak foundations should be avoided, removing the weak material or using a special sequence for the advancement of the deposit, encapsulating the area of weak material. Another alternative is to carry out a foundation treatment, not always a practical approach. Special attention should be given to permafrost conditions as some failures of WRD in Canada have been associated with the melting of ice due to the stresses imposed by the dump. As mentioned previously, a possible sliding triggering mechanism has to be avoided, since major failures and rock flow could be originated.

\subsection{The effect of rain and snow}

The main problem with rain is the possibility of pore water pressure to increase well above foundation level and to produce the flow of fine particles to the bottom of the deposit or the layer, reducing in this way the permeability of the drainage layer. Conservatively designed drains could be required in this case.

The case of snow is also important. Snow will tend to stay on the upper surface of each layer of the WRD in formation or over the advancing slope creating a potential local stability problem. Modifying the construction sequence and advancing with a narrow tongue would allow for the snow to be pushed and thrown into the interior of the dump. Also, to minimise local and global instability, both due to fines and due to snow, building the dump in a transverse manner is proposed, wherever practical (Arcadis, 2006).

In very high WRD the snow deposited over steep slopes could produce snow avalanches in the slope itself. Gentle slopes as well as intermediate berms could help to solve this problem.

\subsection{Designing for closure}

To build a high WRD and then to think of what to do for closure is unthinkable, considering the extraordinary dimensions of these structures. To re-shape a slope with a height of more than $500 \mathrm{~m}$ is something nobody would like to do, not only because of the high costs involved but also for the technical complexity of such an operation. For high WRD, to design considering closure is the most reasonable solution. The practical implications are the need for more gentle general slopes and conservative drainage systems as well as effluent collection and treatment if necessary.

The existence of the intermediate berm in the design will allow also control of possible local snow avalanches, and to contain local slope failures.

\section{Main conclusions}

High waste rock dumps are challenging structures. There is a need to progress in the actual state of the art related to the behavior of waste rock materials subjected to high stresses and to leaching effect, taking into 
account scale effects related to the grain size of rock particles. There are also uncertainties related to the possible modes of failure that could be much more complicated than those analysed by conventional limit equilibrium methods as well as on the research of the mechanics of failure, especially when a flow slide can occur.

The design, operation and construction practice of high WRD should be improved, adopting a number of defensive measures to reduce potential instabilities. Water diversion, snow management and drainage conditions require an important attention for stability and environmental considerations.

The performance of WRD in different environments need to be known based on monitoring and measurements, in order to document lessons learned of the behaviour and performance of these structures. There is the need for designing and manufacturing new and robust instrumentation systems that could survive in a very tough environment with large deformations, heavy rock transport equipment and eventually aggressive chemical environment, allowing remote readings and registration.

\section{Acknowledgements}

The authors wish to express their most sincere thanks to División Andina of Codelco Chile and Anglo American Chile, for supporting most of the applied research that was carried out in relation with high WRD. Thanks are extended to the IDIEM Laboratory and to Professor Ramón Verdugo for their good disposition at accepting suggestions and commenting results during the development of the testing campaign. Special recognition of the authors is due to Professor Norbert Morgenstern for his assistance at the early stages of the high WRD study, recommending many of the analyses that are discussed in the paper.

\section{References}

Arcadis (2006-2007) Internal Report.

Bard, E. (1993) Comportement des matériaux granulaires secs et à liant hydrocarboné. Thèse de Doctorat, Ecole Centrale de Paris, N ${ }^{\circ} 93$ ECAP 0320.

Bard, E., Campaña, J., Anabalón, Ma.E. and Apablaza, R. (2007a) Waste Rock Behaviour under High Pressures. XIII Pan-American Conference on Soil Mechanics and Geotechnical Engineering, Venezuela.

Bard, E., Anabalon, Ma.E., Campaña, J., Apablaza, R. and Gallardo, M. (2007b). Comportamiento de Lastre ROM Sometido a Altas Presiones. VI Congreso Chileno de Ingeniería Geotécnica, Valparaíso.

Biarez, J. and Bard, E. (1992) Loi de Comportement d'un agrégat routier. Analogie avec le comportement des argiles. Volumen Raúl J. Marsal, Sociedad Mexicana de Mecánica de Suelos, A.C.

Bishop, A.W. (1973) The stability of tips and spoil heaps: Quarterly Journal of Engineering Geology, Vol. 6, pp. 335376.

Campbell, D.B. (1986) Stability and performance of waste dumps on steeply sloping terrain, International Symposium on Geotechnical Stability in Surface Mining, Calgary, November, pp. 317-321.

Dawson, R.F., Morgenstern, N.R. and Stokes, A.W. (1998) Liquefaction flowslides in Rocky Mountain coal mine waste dumps. Canadian Geotechnical Journal, Vol. 35, pp. 328-343.

Hungr, O., Dawson, R.F., Kent, A., Campbell, D. and Morgenstern, N.R. (2002) Rapid flow slides of coal-mine waste in British Columbia, Canada. Geological Society of America Reviews in Engineering Geology, Volume XV.

Marsal, R. and Resendiz, D. (1975) Presas de Tierra y Enrocamiento, Editorial Limusa, pp. 221-267.

Morgenstern, N. (1996). Conference International Symposium on Seismic and Environmental Aspects of Dams Design, ICOLD-Santiago, Vol. II, Chile (not published).

Morgenstern, N. (2001, 2006) Personal communications.

Valenzuela, L. (2004) Stability issues in natural and man made slopes in mining. International Conference on Landslides, Brazil.

Valenzuela, L., Bard, E. and Campaña, J. (2007) High Waste Rock Dumps in the Mining Industry. XIII Pan-American Conference on Soil Mechanics and Geotechnical Engineering, Venezuela. 